\title{
Physical and Emotional Sibling Violence in the Time of COVID -19
}

\author{
Nathan H. Perkins ${ }^{1}$ (D) - Abha Rai ${ }^{1}$ - Susan F. Grossman ${ }^{1}$ \\ Accepted: 13 January 2021 / Published online: 8 February 2021 \\ (C) The Author(s), under exclusive licence to Springer Science+Business Media, LLC part of Springer Nature 2021
}

\begin{abstract}
The COVID-19 pandemic has impacted families in a variety of ways with much being written on the potential impact of sheltering in place and quarantining on intimate partner violence and parent-to-child abuse. One area that has received scant attention is that of physical and emotional sibling violence. While physical and emotional sibling violence is a predominant form of family violence, discussion of violence between siblings in the time of COVID-19 has not received the attention it warrants. This article examines the potential for family stress to place siblings at risk for engaging in physical and emotional sibling violence and how this is exacerbated in the time of COVID-19. Also discussed is the the connection between physical and emotional sibling violence and other forms of family violence including intimate partner violence and parent-to-child abuse and neglect which underwrites the need to place physical and emotional sibling violence on the radar of practitioners, policy makers, and researchers. Finally, implications for practice, policy, and research on physical and emotional sibling violence in the context of COVID-19 are discussed.
\end{abstract}

Keywords Sibling violence $\cdot$ Family violence $\cdot$ COVID-19 $\cdot$ Family stress $\cdot$ Practice

\section{Introduction}

COVID-19 has been one of the deadliest pandemics in modern history. According to statistics from the Coronavirus Resource Center at Johns Hopkins University, as of October 20,2020 , there were a total of roughly $40,783,000$ confirmed cases of COVID-19 world-wide with almost one fifth of these cases, approximately 8,300,000 in the United States (Johns Hopkins University, October 22, 2020). The total number of deaths in the United States during this same time period had reached 216,400 (Johns Hopkins University, October 22, 2020). As of October 20, the estimated mortality rate in the U.S., based on the ratio of the number of known cases to the number of deaths was $2.6 \%$, with the United States accounting

Nathan H. Perkins

nperkins2@luc.edu

Abha Rai

arai4@luc.edu

Susan F. Grossman

sgrossm@luc.edu

1 School of Social Work, Loyola University Chicago, 1 E. Pearson St. 526 Maguire Hall, Chicago, IL 60611, USA for approximately $20 \%$ of deaths world-wide due to COVID19 (Johns Hopkins University, October 22, 2020).

Since the start of the pandemic many states have instituted shelter-in-place policies which encouraged individuals to stay at their place of residence except when going to work outside of the home, shopping for groceries, or running essential errands (e.g. doctor visits, getting medications at pharmacy). By April 20, 2020 "at least 316 million people in at least 42 states, three counties, 10 cities, the District of Columbia and Puerto Rico [were] being urged to stay home" in the United States due to the pandemic (Mervosh et al., 2020). These policies were implemented with the hope of slowing the spread of the virus. While there have been and likely will be economic impacts of shelter-in-place policies, a critical unintended consequence are the risks they present to families particularly regarding the risk of family violence. For example, isolation in combination with economic, interpersonal and social stress, especially in relationships where abuse already exists increases the risk of individuals experiencing domestic violence (Berger, 2020; Center for Disease Control, 2019; Godin, 2020; Gupta \& Stahl, 2020; Heise and Garcia-Moreno, 2002; Schwab-Reese, Peek-Asa \& Parker, 2016; Shortt et al., 2013; Snyder, 2020; Taub, 2020; United Nations Entity for Gender Equality and the Empowerment of Women (UNWomen), 2020; Yakubovich et al., 2018; World Health Organization, 2020). These are the very 
conditions frequently created by the pandemic and policies that stress social distancing and quarantining. Social distancing also leaves victims of violence isolated from support systems like family and friends who might otherwise provide respite (World Health Organization (World Health Organization, 2020). It has also affected survivors' ability to access essential services like ongoing support groups or legal and court assistance because agencies are closed or services are provided only online or by phone and victims cannot access technology or speak on the phone safely in their homes (Berger, 2020; Ellis, 2020; Godin, 2020; Gupta \& Stahl, 2020; Selvaratnam, 2020; Southall, 2020; United Nations Entity for Gender Equality and the Empowerment of Women (UNWomen), 2020). Perhaps as a consequence, since the onset of COVID-19, reports of increased domestic violence have been noted world-wide (Berger, 2020; Sigal et al., 2020; Southall, 2020; Taub, 2020; United Nations Entity for Gender Equality and the Empowerment of Women (UNWomen), 2020; Wanqing, 2020; World Health Organization, 2020).

Along with discussions of domestic or intimate partner violence, there have also been discussions about the implications of COVID-19 on child abuse and neglect. Cruz (2020) notes that experts have highlighted the potential for COVID19 to put children at risk for child abuse and neglect due to fewer interactions of children with individuals outside of the home. For example, teachers, doctors, and other mandated reporters are unlikely to have in-person contact with children to ascertain whether abuse is occurring. Furthermore, children are likely not going to call the authorities over experiencing abuse due to the potential ramifications it can have for them. Oftentimes, children may not even have the resources or necessary information to call authorities or agencies to report their ongoing experiences of abuse and neglect. Bryant et al. (2020) also posit that children may experience an increase in adverse childhood experiences as a result of the pandemic. These authors highlight not only the potential for children to experience parent-to-child violence due to family members being in close, constant proximity, but also the potential for children to witness intimate partner violence. Living in close proximity with siblings and lack of supervision by parents may also create a new surge in sibling violence cases.

\section{COVID-19 and Physical and Emotional Sibling Violence}

Compared to other forms of family violence (i.e. child abuse, intimate partner violence, elder abuse), physical and emotional sibling violence (SV) is a neglected field (Perkins \& Grossman, 2019; Simonelli et al., 2005), yet it warrants attention given that children are a marginalized population. SV can be defined as the intent to harm a sibling by using physical (e.g. punching, kicking, choking) or emotional (e.g. threatening, manipulating, insulting) behaviors (Perkins et al., 2017). Sibling violence has been found to be the most common form of family violence (Straus et al., 2006) and has been associated with increased odds of experiencing anxiety, depression, and anger/aggression (Renner et al., 2020). Lower life satisfaction and self-competence (Plamondon et al., 2018), behavior problems and poor peer relations (Stormshak et al., 1996), and suicidal ideation (Bar-Zomer \& Brunstein Klomek, 2018) have been associated with experiencing SV. The occurrence of SV has been found to be a significant predictor of mental health, self-esteem, and delinquency (Tucker et al., 2020a); with SV even being associated with marital conflict (Shalash et al., 2013) and unresolved sibling relationship issues in adulthood (Greif \& Woolley, 2016).

Discussion of SV is also missing from much of the literature regarding the potential effects of COVID-19 on family violence. As of October 26, 2020, a search of publons.com of COVID-19 related publications found no published articles with "sibling" in the title and of the 52 articles published with "violence" in the title, none explicitly discussed SV (Publons, October 26, 2020). Similarly, on October 26, 2020, a search of the authors' university library website with "sibling" and "COVID-19" as keywords in the title produced no results regarding SV. Of the 137 articles that were found on the authors' university library website using "violence" and "COVID-19" in the title, none discussed or mentioned $\mathrm{SV}$. This lack of attention to SV in the literature on COVID19 and violence is indicative of how SV is minimally considered compared to intimate partner violence, child abuse and neglect, and elder abuse (Perkins \& Grossman, 2019) in the literature outside of the context of COVID-19. Perhaps this is because parents have been found to dismiss and ignore violence directed from one sibling toward another (Meyers, 2014; Wiehe, 1997), thereby minimizing the attention SV receives at the familial and societal levels. While the quantity of research and scholarship on SV in general is less than other forms of family violence, the need to consider SV and its harmful impacts now, given the current pandemic context, is essential.

Wolke et al. (2015) highlight that prevalence rates for deleterious behaviors between siblings vary by study, but note that researchers and practitioners agree that this form of family violence is pervasive. In a sample of 54 students aged 18 and older, Skinner and Kowalski (2013) found 78\% reported being bullied by a sibling and $85 \%$ reported bullying a sibling. Bowes et al. (2014) found approximately $48 \%$ of a sample of 6928 children with a mean age of 12 years had been victimized at least once in the previous 6 months by a sibling. Prevalence rates suggest that almost $30 \%$ of children and adolescents aged $0-17$ will experience assault by a sibling at some point in their lifetime (Finkelhor et al., 2015), however these estimates are likely not entirely accurate. In the authors' 
study, parents were asked to report any instances of SV for those aged 0-9 and it is possible that underreporting occurred as parents are likely to not be with children at all times thereby missing some instances of SV (Winters, 2019). Specifically related to COVID-19 and the current functioning of many families, this becomes a salient point because many families may now have children who are interacting for longer periods alone and unsupervised at home, while parents who are at home may be working or overwhelmed with household chores. It is likely in a scenario such as this that an older sibling may be left in charge to maintain control, without any formal training as to how to respond to or manage difficult interpersonal situations. Consequently, during the pandemic, it is entirely possible that the prevalence of SV could be higher due to the social, emotional and economic adjustments families have had to make. In this next section, we identify some of the factors contributing to an increase in SV, particularly in the context of COVID-19. We then discuss the implications of these factors for practitioners, policy advocates and researchers.

\section{COVID-19, Family Stress, and Sibling Violence}

Violence between siblings is not an exception to those things that can be both stressful and traumatic for families (Finkelhor et al., 2006). Regardless the directional association of whether SV leads to familial stress or familial stress leads to SV, it has been indicated that stress in family systems is associated with SV (Eriksen \& Jensen, 2009; Hoffman \& Edwards, 2004; Hoffman et al., 2005; Perkins \& Shadik, 2018). The consequences and ramifications associated with the onset of COVID-19 have likely been stressful for many families as they have faced experiences such as school closures, social isolation, loss of employment, food insecurity, and in some cases loss of loved ones due to COVID-19. Fontanesi et al. (2020) note that parents are likely experiencing psychological distress as a result of worrying about finances, schooling for their children, immobility, social distancing, and a perceived lack of security. Horesh and Brown (2020) argue that "the COVID-19 crisis can and should be viewed from the perspective of trauma" (p.334), and it is likely that the stress experienced by families due to COVID-19 has in many cases led to psychological distress and potentially even trauma. Interestingly, traumatic experiences (termed "family adversity") such as natural disasters, parental unemployment, severe illness of a family member requiring hospitalization, and death of a family member, along with others have collectively been associated with sibling victimization (Tucker et al., 2020b). Given COVID-19 is a type of stressful adversity many families have experienced, it is also likely that SV has not only occurred, but also has occurred in more families due to the stress created by this pandemic.

\section{Connection between Sibling Violence and Other Forms of Family Violence}

As previously noted, there has been concern regarding the potential for increased forms of family violence including intimate partner violence and child abuse as a by-product of COVID-19. As posited by stress theory, stressful situations experienced by families, like COVID-19, may lead to family violence especially if families experience considerable stress and are ill-equipped to address and resolve this stress (Farrington, 1986). While family violence in any capacity is problematic, it is important to again note that $\mathrm{SV}$ often is dismissed, normalized, and ignored (Caspi, 2012; Wiehe, 1997). However, as will be discussed in the following sections, there is a connection between SV and other forms of family violence. Therefore, if there is an increase in intimate partner violence and parent-to-child abuse associated with COVID19 there is also likely cause for concern that instances of $\mathrm{SV}$ are increasing as well.

Domestic Violence/Intimate Partner Violence and Sibling Violence The research examining SV and intimate partner violence and conflict, shows these two forms of family violence are associated. Ruff et al. (2018) found sibling hostility in children $10-15$ years of age to be significantly associated with both mother's and father's reports of marital conflict with their spouse. Similarly, in a national sample of children aged 2 to 9 , comparing those who did and did not experience severe sibling victimization, Tucker et al. (2014) found that interparental conflict was associated with a higher likelihood (1.43 times) of being in the severe sibling victimization group. In that same study, the authors also found that children who witnessed family violence (e.g. parent-to-parent physical, parent-to-parent emotional/ psychological, parent-to-sibling), were 3.22 times more likely to be among those who experienced severe sibling victimization compared to those who experienced no sibling victimization. Early effects of domestic violence and conflict have also been noted to influence sibling bullying. For example, Dantchev and Wolke's (2019b) found in a comparison of children 12 years of age who had and had not been exposed to sibling bullying that being exposed to conflicting partnership and domestic violence from the ages of 0-3 increased the odds of being sibling bully-victims (1.21 for conflicting partnership and 1.29 times for domestic violence comparing those who had and had not been exposed). Finally, using latent class analysis, Ingram et al. (2020) found that greater exposure to family violence and aggression, including witnessing intimate partner violence, increased the odds by 1.82 times of one being in the sibling aggression class compared to those who had experienced low sibling, family, or peer aggression. 
Child Abuse \& Neglect and Sibling Violence Research has indicated that increased levels of stress among parents can be a predictor of child abuse (Abramson, 2020). Research has also shown a connection between parent-to-child abuse and neglect, and SV. In a national sample of children and adolescents aged 5-17, van Berkel et al. (2018) found SV to be significantly correlated with both parent-to-child physical abuse as well as neglect. In her qualitative study on sibling abuse, Meyers (2014) found more than half of the participants had experienced or witnessed parent-to-child abuse. In a secondary data analysis of a national sample including 994 parents with at least two children, Eriksen and Jensen (2006) found parent-to-child physical violence as well as maternal physical corporal punishment to be significant predictors of sibling physical violence. Dantchev and Wolke (2019b) conducted a study examining factors which preceded sibling bullying in the hopes of better understanding those factors influencing the violence between siblings in children at age 12. The authors included two parent-to-child violence variables in their models: "suboptimal parenting" defined as parental hitting, shouting, hostility, or resentment toward a child and "child maltreatment" which included a child taken out of the home and/or child experienced violence from a family member or stranger (p.1062). While child maltreatment was not a predictor of being a victim of sibling bullying, children were 1.13 times more likely to be a sibling bully-victim and 1.23 times more likely to be a sibling bully if they experienced suboptimal parenting compared to those who experienced no sibling bullying in their relationship with a sibling.

Parental Supervision and Sibling Violence Although arguably lack of parental supervision is not synonymous with parental neglect, parental supervision may impact the occurrence of SV (Winters, 2019) especially in the times of COVID-19 if older siblings are potentially taking on more parentified roles. Parents working outside or even inside the home due to COVID-19 are potentially at risk of burnout, thereby increasing their potential for not only child abuse and neglect (Griffith, 2020), but also for decreased parental supervision of their children's interactions. Research has shown parental employment to be associated with less parental supervision and more childcare from older to younger siblings (Capizzano et al., 2004). Lack of parental supervision is a situation where children are left to address conflict themselves and may not know how to effectively and positively interact (Caspi, 2012). Children may not be equipped to deal with the "crisis" of SV and may even mishandle the situation or create further harm. Situations surrounding SV may be traumatic both for the child who causes abuse and the one who experiences it. A decrease in parental supervision of children may lead to increased SV as children deal with conflictual situations themselves that may lead to violence. Also, a lack of supervision may perpetuate the minimization of the importance of addressing SV because if parents do not see it, then they may misguidedly think it does not happen between their children. Lack of parental supervision, however, has been connected to instances of SV (Perkins \& Shadik, 2014; Winters, 2019).

In a secondary data analysis of the Developmental Victimization Survey 2002-2003 which included the Juvenile Victimization Questionnaire (Hamby et al., 2004), Perkins and Shadik (2014) found that lower parental supervision significantly predicted higher instances of sibling physical violence in children and adolescents aged $0-17$. In her recently completed dissertation, Winters (2019) found lack of parental supervision to be a family condition that was associated with the occurrence of SV. Regarding participants in her study, Winters notes that "without adequate supervision, siblings engaged in patterns of abusive physical and emotional violence within family-wide coercive processes that spanned changing family configurations and years of their young lives" (p.111). Lack of parental supervision was so pervasive it occurred in 7 out of the 8 participants included in her study. In sum, given that the literature suggests SV is associated with domestic violence and child abuse as well as decreased parental supervision, and that all of these conditions have been exacerbated by the COVID-19 pandemic and the policies put in place to try to control the spread of the disease, we can expect that SV will also have increased over the past few months and that it will continue to do so. Yet, we have limited empirical evidence and no system in place to document the occurrence of SV, nor do we have policies specifically designed to address its impact and prevent further incidence through practice. With this in mind, we next consider implications for practice, policy and research.

\section{Implications for Practice, Research, and Policy}

While absolutely pertinent before COVID- 19 , the need to assess for, intervene, address, prevent, and ameliorate $\mathrm{SV}$ is warranted even more as the pandemic has led to increased stress for many families and also altered the way in which many families are functioning. For many children, traumainformed resources and care are provided at schools (Phelps $\&$ Sperry, 2020), yet most schools are closed and if they do open, they likely will remain altered in some fashion such that ancillary supports provided outside of time in classes will be restricted. As second or third waves of COVID-19 occur, schools could close or be substantially impacted thereby limiting child access to needed mental health and trauma supports. For those social workers and mental health practitioners working within schools, it is imperative they ask families and children about relationships between siblings in the home. The dynamics between siblings could be different across communities and cultures. For example, in certain cultures gender may influence the power one sibling may have over the other 
(Rai, 2020; Rai et al., 2020). Therefore, it is imperative that school social workers and counselors engaging with children either through in-person or zoom sessions, are trained to be culturally responsive to the needs of diverse families and communities. Furthermore, practitioners working with families outside of school environments also need to include assessment of SV, along with assessing for intimate partner violence and parent-to-child abuse, in the questions they ask parents and children.

Stutey (2017) notes that along with assessing for SV, practitioners need to work with families to help with their conceptualization of SV. Stutey states that psychoeducation around what constitutes SV, including making a plan for safety, and evaluation of interventions will help families understand this form of family violence and the need for better supervision of siblings and how they interact. Equipping parents with the necessary information and tools to adequately address SV may empower parents to take a more active role in the dynamics among siblings living in a home.

Although not specifically focused on SV, several media articles have discussed with experts in the field what families should consider regarding sibling relationships in the time of COVID-19. Laurie Kramer, a professor of applied psychology at Northeastern University, notes that parents can help their children try and understand the perspective of their sibling to use as a tool to manage conflicts (Candanosa, 2020). Along with parents using a non-judgemental tone with children when there is conflict, Kramer notes that if siblings are able to better understand their sibling's perspective it may lead to empathy thereby potentially decreasing the likelihood of conflict.

In a CNN article on sibling rivalry, Hunt (2020) presents information from leading experts on sibling relationships regarding the potential impact of the pandemic. Hunt presents that both positive and negative interactions can happen between siblings and includes some preliminary research from Claire Hughes, a professor of developmental psychology at the University of Cambridge's Center for Family Research, who is currently conducting a study on the impact of COVID-19 on sibling relationships. Early results indicate that two-thirds of families report stronger sibling relationships. However, as Hughes notes, those parents who are filling out the online survey are likely to have more time and more resources to engage in the research. Therefore, these parents are likely more involved with their children as they have the time and means to do so. This may not be the case for many families especially families of different cultures and contexts. Immigrant families in particular may be experiencing considerable stress due to having frontline jobs as well as a greater likelihood of having lost a job due to the pandemic while also being more vulnerable to COVID-19 because of a lack of resources (Chishti \& Bolter, 2020). For families with limited or no resources, culturally responsive interventions to help address and intervene when SV occurs are needed to help reduce stress within the family system.
Unfortunately, much of the research regarding SV in the U.S. has been conducted with samples and participants who are predominantly Caucasian and middle-class. Research outside of the U.S., however, demonstrates that SV occurs in other ethnic groups (for example see Chen, 2019; Haj-Yahia \& Dawud-Noursi, 1998; Kim \& Kim, 2019). It is likely that $\mathrm{SV}$ is an issue for families regardless of ethnicity and therefore intervention efforts need to be considered for all families regardless of ethnicity. For example, in immigrant, nonWestern, and agrarian families, older siblings often have the added responsibility of supporting their families in taking care of their younger siblings (Zukow-Goldring, 2002). This pressure may lead to feelings of distress and increased instances of SV especially if older siblings lack needed skills or training to effectively address and resolve conflict in a positive way (Caspi, 2012). Practitioners need to assess and attend to instances of SV in all families and find mechanisms to be culturally sensitive to differences in the conceptualization of SV; especially since there is a clear dearth of knowledge of how children, parents, and families from various cultures experience SV (Rapoza et al., 2010). It is vital for researchers to directly engage with diverse families to deconstruct SV and the tactics associated with it across diverse cultures. Doing so, will not only allow researchers and practitioners to develop a more expansive definition of $\mathrm{SV}$, but also provide community-led and culturally responsive solutions in cases of SV.

Along with diverse samples, future research also needs to be conducted to examine the longitudinal impact of COVID19 on SV. The vast majority of research studies examining SV and negative/harmful behaviors have been cross-sectional, thereby limiting discussion of causality due to the inability to determine if SV came before negative/harmful behaviors or vice versa. However, several recent studies looking specifically at sibling bullying have been longitudinal and have included large samples allowing the researchers to examine factors contributing to the occurrence of sibling bullying as well as those outcomes that can be attributed to sibling bullying (see Dantchev \& Wolke, 2019a, 2019b; Dantchev et al., 2018). Future longitudinal research on SV with large samples is likely to provide insight into the impact of COVID-19 on sibling relationships throughout the life course.

We also need to make sure that policy makers understand the problem of SV, particularly when it is likely to be even more prevalent during the pandemic and provide appropriate resources to practitioners who are working with families. In the short term, this includes funds for training as well and for the provision of resources that can help with education, intervention and prevention efforts. Policymakers should also consider funding educational initiatives to increase public awareness and knowledge about SV. Currently, there are no specific existing laws related to SV (Perkins \& Grossman, 2019). Policies such as the Violence Against Women Act of 1994, 
which contributed to the decrease in violence against women through 2008 (Catalano et al., 2009) could serve as a model for the conceptualization, creation, and implementation of policy to address SV. Inclusion of SV in policies, such as failure to protect laws, that hold parents accountable when SV occurs between their children may be a start toward the creation of policy specifically addressing SV (Perkins \& Barry, 2020).

\section{Conclusion}

In the time of COVID-19, many families are likely experiencing incredible stress that impacts the many facets of family life. Family stress may potentially impact whether and how SV occurs. Given the focus that has been placed on intimate partner violence and parent-to-child abuse due to COVID-19 as well as the association between these forms of family violence and SV, SV needs to be on the radar of practitioners working with children, parents, and families, as well as researchers who examine family violence. To not consider SV is to disregard what is arguably one of the most common forms of family violence and to do so in the time of COVID-19 is to neglect what may be transpiring in many families regardless of culture or context. Efforts to intervene and help families address and prevent SV, may provide families with essential assistance and tools to decrease stress, and function in a more harmonious way which is undoubtedly needed right now. This paper is an urgent call to researchers, practitioners and policy lobbyists to actively engage in conversations, research and community-training about $\mathrm{SV}$ which is possibly seeing a surge during this pandemic, without even being recognized.

\section{References}

Abramson, A. (2020, April 8). How COVID-19 may increase domestic violence and child abuse. American Psychological Association https://www.apa.org/topics/covid-19/domestic-violence-childabuse.

Bar-Zomer, J., \& Brunstein Klomek, A. (2018). Attachment to parents as a moderator in the association between sibling bullying and depression or suicidal ideation among children and adolescents. Frontiers in Psychiatry, 9, 72. https://doi.org/10.3389/fpsyt.2018.00072.

Berger, M. (2020, April 1). Measures to control the spread of coronavirus are a nightmare for victims of domestic violence. Advocates are demanding governments step up. Washington Post. https://www. washingtonpost.com/world/2020/04/01/measures-control-spreadcoronavirus-are-nightmare-victims-domestic-violence-advocatesare-demanding-that-governments-step-up/

Bowes, L., Wolke, D., Joinson, C., Lereya, S. T., \& Lewis, G. (2014). Sibling bullying and risk of depression, anxiety, and self-harm: A prospective cohort study. Pediatrics, 134(4), e1032-e1039. https:// doi.org/10.1542/peds.2014-0832.
Bryant, D. J., Oo, M., \& Damian, A. J. (2020). The rise of adverse childhood experiences during the COVID-19 pandemic. Psychological Trauma: Theory, Research, Practice, and Policy, 2(999), 1-2. https://doi.org/10.1037/tra0000711.

Candanosa, R. M. (2020, April 8). Home during the COVID-19 pandemic? It's an opportunity to help your kids get along. Medicalexpress. https://medicalxpress.com/news/2020-04-home-covid-pandemicopportunity-kids.html

Capizzano, J., Main, R., \& Nelson, S. (2004). Adolescents assuming adult roles: Factors associated with teens providing child care for younger siblings. The Urban Institute. https://files.eric.ed.gov/fulltext/ ED485865.pdf

Caspi, J. (2012). Sibling aggression: Assessment and treatment. New York: Springer.

Catalano, S., Smith, E., Snyder, H., \& Rand, M. (2009, September). Selected findings: Female victims of violence. Bureau of Justice Statistics. https://www.bjs.gov/content/pub/pdf/fvv.pdf

Center for Disease Control (2019, October 8). Intimate partner violence: Risk and protective factors for perpetration. https://www.cdc.gov/ violenceprevention/intimatepartnerviolence/riskprotectivefactors. html

Chen, B. B. (2019). Chinese mothers' sibling status, perceived supportive coparenting, and their children's sibling relationships. Journal of Child and Family Studies, 28(3), 684-692. https://doi.org/10.1007/ s10826-018-01322-3.

Chishti, M., \& Bolter, J. (2020, April 24). Vulnerable to COVID-19 and in frontline jobs, immigrants are mostly shut out of U.S. Relief. Migration Policy Institute. https://www.migrationpolicy.org/article/ covid19-immigrants-shut-out-federal-relief

Cruz, A. (2020, April 14). Coronavirus puts children at an increased risk for abuse and neglect: Experts. ABC7Chicago. https://abc7chicago. $\mathrm{com} /$ coronavirus-puts-children-at-an-increased-risk-for-abuse-andneglect-experts/6102182/

Dantchev, S., \& Wolke, D. (2019a). Sibling bullying at 12 years and high-risk behavior in early adulthood: A prospective cohort study. Aggressive Behavior, 45(1), 18-32. https://doi.org/10.1002/ab. 21793.

Dantchev, S., \& Wolke, D. (2019b). Trouble in the nest: Antecedents of sibling bullying victimization and perpetration. Developmental Psychology, 55(5), 1059-1071. https://doi.org/10.1037/ dev0000700.

Dantchev, S., Zammit, S., \& Wolke, D. (2018). Sibling bullying in middle childhood and psychotic disorder at 18 years: A prospective cohort study. Psychological Medicine, 48(14), 2321-2328. https:// doi.org/10.1017/S0033291717003841.

Ellis, E.G. (2020, April 28). Tech is a double-edged lifeline for domestic violence victims. Wired. https://www.wired.com/story/covid-19coronavirus-domestic-violence/

Eriksen, S., \& Jensen, V. (2006). All in the family? Family environment factors in sibling violence. Journal of Family Violence, 21(8), 497507. https://doi.org/10.1007/s10896-006-9048-9.

Eriksen, S., \& Jensen, V. (2009). A push or a punch: Distinguishing the severity of sibling violence. Journal of Interpersonal Violence, 24(1), 183-208. https://doi.org/10.1177/0886260508316298.

Farrington, K. (1986). The application of stress theory to the study of family violence: Principles, problems, and prospects. Journal of Family Violence, 1(2), 131-147.

Finkelhor, D., Turner, H., \& Ormrod, R. (2006). Kid's stuff: The nature and impact of peer and sibling violence on younger and older children. Child Abuse \& Neglect, 30(12), 1401-1421. https://doi.org/10. 1016/j.chiabu.2006.06.006.

Finkelhor, D., Turner, H. A., Shattuck, A., \& Hamby, S. L. (2015). Prevalence of childhood exposure to violence, crime, and abuse: Results from the National Survey of Children's exposure to violence. JAMA Pediatrics, 169(8), 746-754. https://doi.org/10.1001/ jamapediatrics.2015.0676. 
Fontanesi, L., Marchetti, D., Mazza, C., Di Giandomenico, S., Roma, R., $\&$ Verrocchio, M. C. (2020). The effect of the COVID-19 lockdown on parents: A call to adopt urgent measures. Psychological Trauma: Theory, Research, Practice, and Policy. (advance online publication). https://doi.org/10.1037/tra0000672.

Godin, M. (2020, March 18). As cities around the world go on lockdown, victims of domestic violence look for a way out. Time. https://time. com/5803887/coronavirus-domestic-violence-victims/.

Greif, G. L., \& Woolley, M. E. (2016). Adult sibling relationships. NY: Columbia University Press.

Griffith, A. K. (2020). Parental burnout and child maltreatment during the COVID-19 pandemic. Journal of Family Violence. Advance online publication. https://doi.org/10.1007/s10896-020-00172-2.

Gupta, A. H., \& Stahl, A. (2020, June 18). For abused women, a pandemic lockdown holds dangers of its own. New York Times. https:// www.nytimes.com/2020/03/24/us/coronavirus-lockdowndomestic-violence.html.

Haj-Yahia, M. M., \& Dawud-Noursi, S. (1998). Predicting the use of different conflict tactics among Arab siblings in Israel: A study based on social learning theory. Journal of Family Violence, 13(1), 81-103. https://doi.org/10.1023/A:1022864801027.

Hamby, S. L., Finkelhor, D., Ormrod, R. K., \& Turner, H. A. (2004). The comprehensive juvenile victimization questionnaire. Durham, $\mathrm{NH}$ : Crimes against Children Research Center.

Heise, L., \& Garcia-Moreno, C. (2002). Chapter 4. Violence by intimate partners. In Krug, Etienne G., Dahlberg, Linda L., Mercy, James A., Zwi, Anthony B., and Lozano, Rafael (Eds.). World report on violence and health, pp 87-122. World Health Organization. Avaiable online at: https://apps.who.int/iris/bitstream/handle/10665/42495/9241545615 eng.pdf;jsessionid=E76B99BBF963D59DD949D71A6A188608? sequence $=1$

Hoffman, K. L., \& Edwards, J. N. (2004). An integrated theoretical model of sibling violence and abuse. Journal of Family Violence, 19(3), 185-200. https://doi.org/10.1023/B:JOFV.0000028078.71745.a2.

Hoffman, K. L., Kiecolt, K. J., \& Edwards, J. N. (2005). Physical violence between siblings a theoretical and empirical analysis. Journal of Family Issues, 26(8), 1103-1130. https://doi.org/10.1177/ 0192513 X05277809.

Horesh, D., \& Brown, A. D. (2020). Traumatic stress in the age of COVID-19: A call to close critical gaps and adapt to new realities. Psychological Trauma: Theory, Research, Practice, and Policy, 12(4), 331-335. https://doi.org/10.1037/tra0000592.

Hunt, K. (2020, May 19). The pandemic is testing sibling rivalry-and you. CNN. https://www.cnn.com/2020/05/19/health/sibling-rivalrypandemic-wellness/index.html

Ingram, K. M., Espelage, D. L., Davis, J. P., \& Merrin, G. J. (2020). Family violence, sibling, and peer aggression during adolescence: Associations with behavioral health outcomes. Frontiers in Psychiatry, 11, 26. https://doi.org/10.3389/fpsyt.2020.00026.

Johns Hopkins University and Medicine, Coronavirus Resource Center (October 20, 2020). Downloaded October 22, 2020 from: https:// coronavirus.jhu.edu/us-map

Kim, J., \& Kim, E. (2019). Bullied by siblings and peers: The role of rejecting/neglecting parenting and friendship quality among Korean children. Journal of Interpersonal Violence, 34(11), 2203-2226. https://doi.org/10.1177/0886260516659659.

Mervosh, S., Lu, D., \& Swales, V. (2020, April 20). See which states and cities have told residents to stay at home. The New York Times. https://www.nytimes.com/interactive/2020/us/coronavirus-stay-athome-order.html

Meyers, A. (2014). A call to child welfare: Protect children from sibling abuse. Qualitative Social Work, 13(5), 654-670. https://doi.org/10. $1177 / 1473325014527332$.

Perkins, N. H., \& Shadik, J. A. (2014). The intersection of sibling violence and child abuse and neglect. Poster presented at the 22nd annual american professional society on the abuse of children colloquium, New Orleans, LA.

Perkins, N. H., Coles, C., \& O'Connor, M. K. (2017). Physical and emotional sibling violence and policy: An examination of Fox-Harding's child care value perspectives. Child \& Youth Services, 38(1), 4-23.

Perkins, N. H., \& Barry, J. (2020). Should failure to protect laws include physical and emotional sibling violence? Child \& Family Social Work, 25, 206-209. https://doi.org/10.1111/cfs.12643.

Perkins, N. H., \& Grossman, S. F. (2019). Sibling violence. Advances in social work, 19(1), 138-156.

Perkins, N. H., \& Shadik, J. A. (2018). A parent's perceptions of physical and emotional sibling violence. Families in society: The Journal of Contemporary Social Services, 99(1), 78-86.

Phelps, C., \& Sperry, L. L. (2020). Children and the COVID-19 pandemic. Psychological Trauma: Theory, Research, Practice, and Policy. Advance online publication. https://doi.org/10.1037/tra0000861.

Plamondon, A., Bouchard, G., \& Lachance-Grzela, M. (2018). Family dynamics and young adults' well-being: The mediating role of sibling bullying. Journal of Interpersonal Violence. Advance Online Publication., 088626051880031. https://doi.org/10.1177/ 0886260518800313.

Publons (July 7, 2020). COVID-19 related publications. Downloaded July 7, 2020 from: https://publons.com/publon/covid-19/

Rai, A. (2020). Indirect experiences with domestic violence and helpgiving among South Asian immigrants in the United States. Journal of Community Psychology, 1-20. https://doi.org/10.1002/ jcop.22492.

Rai, A., Grossman, S. F., \& Perkins, N. H. (2020). The impact of COVID19 on family violence in immigrant communities in the United States. Greenwich Social Work Review, 1(2), 84-96.

Rapoza, K. A., Cook, K., Zaveri, T., \& Malley-Morrison, K. (2010). Ethnic perspectives on sibling abuse in the United States. Journal of Family Issues, 31(6), 808-829. https://doi.org/10.1177/ 0192513 X09359158.

Renner, L. M., Schwab-Reese, L. M., Coppola, E. C., \& Boel-Studt, S. (2020). The contribution of interpersonal violence victimization types to psychological distress among youth. Child Abuse \& Neglect, 106, 104493. https://doi.org/10.1016/j.chiabu.2020. 104493.

Ruff, S. C., Durtschi, J. A., \& Day, R. D. (2018). Family subsystems predicting adolescents' perceptions of sibling relationship quality over time. Journal of Marital \& Family Therapy, 44(3), 527-542. https://doi.org/10.1111/jmft.12265.

Schwab-Reese, L. M, Peek-Asa C., \& Parker, E. (2016). Associations of financial stressors and physical intimate partner violence perpetration Injury Epidemiology, 3(1): 6 https://doi.org/10.1186/s40621016-0069-4.

Selvaratnam, T. (2020, March 23). Where can domestic violence victims turn during COVID-19? New York Times. https://www.nytimes. com/2020/03/23/opinion/covid-domestic-violence.html? searchResultPosition $=3$.

Shalash, F. M., Wood, N. D., \& Parker, T. S. (2013). Our problems are your sibling's fault: Exploring the connections between conflict styles of siblings curing adolescence and later adult committed relationships. American Journal of Family Therapy, 41(4), 288-298. https://doi.org/10.1080/01926187.2012.698205.

Shortt, J. W., Capaldi, D. M., Kim, H. K., \& Tiberio, S. S. (2013). The interplay between interpersonal stress and psychological intimate partner violence over time for young at -risk couples. Journal of Adolescence, 42, 619-632. https://doi.org/10.1007/s10964-0139911-y.

Sigal, L., Miranda, N. A. M., Martinez, A. I., \& Machicao, M. (2020, April 27). 'Another pandemic': In Latin America, domestic abuse rises amid lockdown. Reuters. https://www.reuters.com/article/ushealth-coronavirus-latam-domesticviol/another-pandemic-in-latinamerica-domestic-abuse-rises-amid-lockdown-idUSKCN2291JS 
Simonelli, C. J., Mullis, T., \& Rohde, C. (2005). Scale of negative family interactions: A measure of parental and sibling aggression. Journal of Interpersonal Violence, 20(7), 792-803. https://doi.org/10.1177/ 0886260505277102

Skinner, J. A., \& Kowalski, R. M. (2013). Profiles of sibling bullying. Journal of Interpersonal Violence, 28(8), 1726-1736. https://doi. org/10.1177/0886260512468327.

Snyder, R. L. (2020, March 16). Trapped at home: Coronavirus could be disastrous for domestic violence victims. Los Angeles Times. https:// www.latimes.com/entertainment-arts/story/2020-03-16/socialdistancing-coronavirus-domestic-violence.

Southall, A. (2020, April 17). Why a drop in domestic violence reports might not be a good sign. New York Times. https://www.nytimes. com/2020/04/17/nyregion/new-york-city-domestic-violencecoronavirus.html

Stormshak, E. A., Bellanti, C. J., \& Bierman, K. L. (1996). The quality of sibling relationships and the development of social competence and behavior control in aggressive children. Developmental Psychology, 32(1), 79-89. https://doi.org/10.1037/0012-1649.32.1.79.

Straus, M. A., Gelles, R. J., \& Steinmetz, S. K. (2006). Behind closed doors: Violence in the American family (2nd ed.). New Brunswick, NJ: Transaction Publishers.

Stutey, D.M. (2017, February 28). Helping children and families address and prevent sibling abuse. Counseling Today. https:/ct.counseling. org/2017/02/helping-children-families-address-prevent-siblingabuse/

Taub, A. (2020, April 6). A new covid-19 crisis: Domestic abuse rises worldwide. New York Times. https://www.nytimes.com/2020/04/ 06/world/coronavirus-domestic-violence.html.

Tucker, C. J., Finkelhor, D., Turner, H., \& Shattuck, A. M. (2014). Family dynamics and young children's sibling victimization. Journal of Family Psychology, 28(5), 625-633. https://doi.org/10. 1037/fam0000016.

Tucker, C. J., Finkelhor, D., \& Turner, H. A. (2020a). Family and friend social support as mediators of adolescent sibling victimization and mental health, self-esteem, and delinquency. American Journal of Orthopsychiatry. Advance online publication, 90, 703-711. https:// doi.org/10.1037/ort0000502.

Tucker, C. J., Finkelhor, D., \& Turner, H. A. (2020b). Family predictors of sibling versus peer victimization. Journal of Family Psychology, 34(2), 186-195. https://doi.org/10.1037/fam0000592.
United Nations Entity for Gender Equality and the Empowerment of Women (UNWomen). (2020) COVID-19 and ending violence against women and girls. Accessed April 29, $2020 \mathrm{https}: / /$ www. unwomen.org/-/media/headquarters/attachments/sections/library/ publications/2020/issue-brief-covid-19-and-ending-violenceagainst-women-and-girls-en.pdf?la=en\&vs=5006

van Berkel, S. R., Tucker, C. J., \& Finkelhor, D. (2018). The combination of sibling victimization and parental child maltreatment on mental health problems and delinquency. Child Maltreatment, 23(3), 244 253. https://doi.org/10.1177/1077559517751670.

Violence Against Women Act of 1994, 42 U.S.C. §§ 13701 (1994).

Wanqing, Z. (2020, March 2). Domestic violence cases surge during COVID-19 epidemic. Sixth Tone. https://www.sixthtone.com/ news/1005253/domestic-violence-cases-surge-during-covid-19epidemic

Wiehe, V. R. (1997). Sibling abuse: Hidden physical, emotional, and sexual trauma (2nd ed.). Thousand Oaks, CA: Sage.

Winters, K. E. (2019). Physical and emotional sibling violence and child welfare: A critical realist exploratory study (unpublished doctoral dissertation). Retrieved from ProQuest Dissertations and Theses Database (No. 13806345).

Wolke, D., Tippett, N., \& Dantchev, S. (2015). Bullying in the family: Sibling bullying. The Lancet: Psychiatry, 2(10), 917-929. https:// doi.org/10.1016/S2215-0366(15)00262-X.

World Health Organization (2020, April 15). Violence against women during COVID-19. https://www.who.int/news-room/q-a-detail/ violence-against-women-during-covid-19

Yakubovich, A. R., Stockl, H., Murray, J., Melendez-Torres, G. J., Steinert, J. I., Glavin, C. E. Y., \& Humphreys, D. K. (2018). Risk and protective factors for intimate partner violence against women: Systematic review and meta-analyses of prospective longitudinal studies. American Journal of Public Health, 108(7), E1-E11. https://doi.org/10.2105/AJPH.2018.304428.

Zukow-Goldring, P. (2002). Sibling caregiving. In M. H. Bornstein (Ed.), Handbook of parenting: Being and becoming a parent (Vol. 3, 2nd ed., pp. 253-286). Mahwah, NJ: Lawrence Erlbaum.

Publisher's Note Springer Nature remains neutral with regard to jurisdictional claims in published maps and institutional affiliations. 